\title{
ABA Is Required for Leptosphaeria maculans Resistance via ABI1- and ABI4-Dependent Signaling
}

\author{
Maria Kaliff, Jens Staal, Mattias Myrenås, and Christina Dixelius \\ Department of Plant Biology and Forest Genetics, Swedish University of Agricultural Sciences, P.O. Box 7080, \\ 75007 Uppsala, Sweden
}

Submitted 30 August 2006. Accepted 19 October 1006.

\begin{abstract}
Abscisic acid (ABA) is a defense hormone with influence on callose-dependent and -independent resistance against Leptosphaeria maculans acting in the $R L M 1_{\text {Col }}$ pathway. ABAdeficient and -insensitive mutants in Ler-0 background (aba1-3 and abil-1) displayed susceptibility to L. maculans, along with a significantly decreased level of callose depositions, whereas abi2-1 and abi3-1 remained resistant, together with the abi5-1 mutant of Ws-0 background. Suppressor mutants of abil-1 confirmed that the $L$. maculans-susceptible response was due to the dominant negative nature of the abil-1 mutant. Highly induced camalexin levels made ABA mutants in Col-0 background (aba2-1, aba3-1, and abi4-1) appear resistant, but displayed enhanced susceptibility as double mutants with pad3-1, impaired in camalexin biosynthesis. $\beta$-Aminobutyric acid (BABA) pretreatment of Ler-0 contributed to an elevated level of endogenous ABA after $L$. maculans inoculation. Comparisons between $\left(R L M 1_{\mathrm{Col}}\right)$ pad3 and $r \operatorname{lm} 1_{\mathrm{Ler}}$ pad3 showed that ABA and BABA enhancement of callose deposition requires induction from $R L M 1_{\mathrm{Col}} \cdot A B I 1$, but not $A B I 2$, was found to be involved in a feedback mechanism that modulates $R L M 1_{\mathrm{Col}}$ expression. Genetic analysis showed further that this feedback occurs upstream of $A B I 4$ and that components downstream of $A B I 4$ modulate $A B I 1$ activity. ABA and BABA treatments of the $L$. maculans-susceptible callose synthase mutant pmr4 showed that ABA also induces a callose-independent resistance. Similar treatments enhanced callose depositions and induced resistance to $L$. maculans in oilseed rape, and BABA-induced resistance was found to be independent of salicylic acid.
\end{abstract}

Additional keywords: Arabidopsis, defense, resistance gene.

Several pathways playing crucial roles in plant defense signaling are well documented, not least the roles of salicylic acid (SA), jasmonic acid (JA), and ethylene (ET) (Glazebrook 2005; Hammond-Kosack and Parker 2003). In comparison, not much is known about the impact on defense responses of other types of plant hormones, such as abscisic acid (ABA). ABA regulates many aspects of plant growth and development, in-

M. Kaliff and J. Staal contributed equally to this work.

Corresponding author: M. Kaliff; E-mail: Maria.Kaliff@vbsg.slu.se: Fax: +4618673389.

*The $e$-Xtra logo stands for "electronic extra" and indicates the HTML abstract available online contains supplemental material not included in the print edition. Two additional figures and one additional table appear online. cluding embryo maturation, seed dormancy, abiotic stress responses, leaf senescence, and stomatal aperture (Zeevaart and Creelman 1988). Transcriptome analyses have unraveled more than a thousand genes that are differentially regulated by ABA, clearly demonstrating the complexity of ABA signaling (Hoth et al. 2002; Sánchez et al. 2004; Seki et al. 2002). In biotic stress-related studies, exogenous application of ABA caused enhanced pathogen susceptibility due to the suppression of SA in various plant species (Audenaert et al. 2002; McDonald and Cahill 1999; Mohr and Cahill 2003; Rezzonico et al. 1998). By analogy, ABA-deficient tomato plants were more resistant to infection by the bacterial pathogen Pseudomonas syringae pv. tomato (Thaler and Bostock 2004). In addition to interference of the SA-dependent defense pathway (Audenaert et al. 2002), antagonistic interactions between ABA and JA or ET signaling have been shown to modulate defense gene expression in response to the vascular fungal pathogen Fusarium oxysporum (Anderson et al. 2004).

In most cases, $\mathrm{ABA}$ biosynthesis is repressed after pathogen challenge; however, in some cases, such as after viral infection in tobacco, it can be induced (Whenham et al. 1986). The changes in endogenous ABA levels, however, are relatively moderate when compared with the changes observed in the biosynthesis of SA, ET, or JA after pathogen challenge (Mauch-Mani and Mauch 2005). A positive role for ABA in defense against Alternaria brassicicola and Plectosphaerella cucumerina was revealed following $\beta$-aminobutyric acid (BABA) treatments (Ton and Mauch-Mani 2004). BABAinduced resistance (IR) against the two necrotrophic fungi was found to act through the priming of callose depositions and the resistance was impaired in the callose synthase mutant pmr4-1 and the ABA-deficient and -insensitive mutants abal-5 and abi4-1. The effects seen from BABA-IR also could be obtained by application of $\mathrm{ABA}$, demonstrating that the priming for callose was an ABA-dependent mechanism (Ton and MauchMani 2004). BABA, on the other hand, was found to enhance the sensitivity of the plant to ABA, resulting in resistance to salinity and drought stress after BABA pretreatment (Jakab et al. 2005). Callose deposition is dependent on vesicular secretion and regulation of specific SNARE (soluble NSF attachment receptor) proteins, representing another proposed mechanism for ABA-primed callose deposition (Mauch-Mani and Mauch 2005; Ton et al. 2005). Additional positive roles for ABA in pathogen defense have been observed in interactions with an oxalate-deficient Sclerotinia sclerotiorum mutant, where the regulation of guard cells was found to be the major mechanism of resistance (Guimaraes and Stotz 2004). Clearly, the role of ABA in plant defense signaling is complex and also may vary 
between pathosystems. The mechanisms behind BABA-IR remain unclear; however, in addition to the ABA-dependent priming for callose depositions, BABA-induced priming of the systemic aquired resistance signaling pathway contributed to resistance to Botrytis cinerea, Hyaloperonospora parasitica, and Pseudomonas syringae (Zimmerli et al. 2000, 2001).

Resistance against Leptosphaeria maculans recently was found to be dependent on callose depositions, induced by the Drosophila TOLL and human interleukin-1-receptor (TIR) nucleotide binding site (NB) leucine-rich repeat (LRR) encoded resistance gene $R L M 1_{\mathrm{Col}}$ (Staal et al. 2006). The $R L M 1_{\mathrm{Col}}$ and $R L M 2_{\mathrm{Ler}}$ loci were identified via transgressive segregation in progenies between Col-0 $\left(R L M 1_{\mathrm{Col}} r l m 2_{\mathrm{Col}}\right)$ and Ler- 0 $\left(r l m 1_{\mathrm{Ler}} R L M 2_{\mathrm{Ler}}\right)$ and further genomic data showed that the two loci have a common evolutionary history, indicating that the two genes are paralogs and functionally redundant (Staal et al. 2006). To expand our knowledge of signaling pathways in this plant-pathogen system, we evaluated the importance of endogenous ABA levels and the role of exogenously applied BABA for resistance responses in Arabidopsis. The earlier established link between $R L M 1_{\mathrm{Col}}$ and callose led us to investigate whether ABA acts in the $R L M 1_{\mathrm{Col}}$ pathway. This was accomplished through observations of $\mathrm{ABA}$ induction after $L$. maculans stress, complementation of $r \operatorname{lm} 1_{\mathrm{Ler}} r \operatorname{lm} 2$ genotypes via $A B A$ treatments, and observations of callose deficiencies in mutants impaired in endogenous ABA. Because L. maculans is a devastating pathogen on Brassica crops (Howlett et al. 2001; Salisbury et al. 1995), we translated the information obtained from Arabidopsis to comparative defense studies on Brassica napus. Our results suggest that $\mathrm{ABA}$ acts as a pathogen defense hormone in the $R L M 1_{\mathrm{Col}}$ pathway and, in addition to enhancement of callose deposition, induces a broader array of defense responses than earlier anticipated.

\section{RESULTS}

Ler-0 mutants impaired in ABA biosynthesis and signaling are susceptible to $L$. maculans.

An assessment of Arabidopsis mutants to explore novel key defense factors in the L. maculans plant-pathogen system was

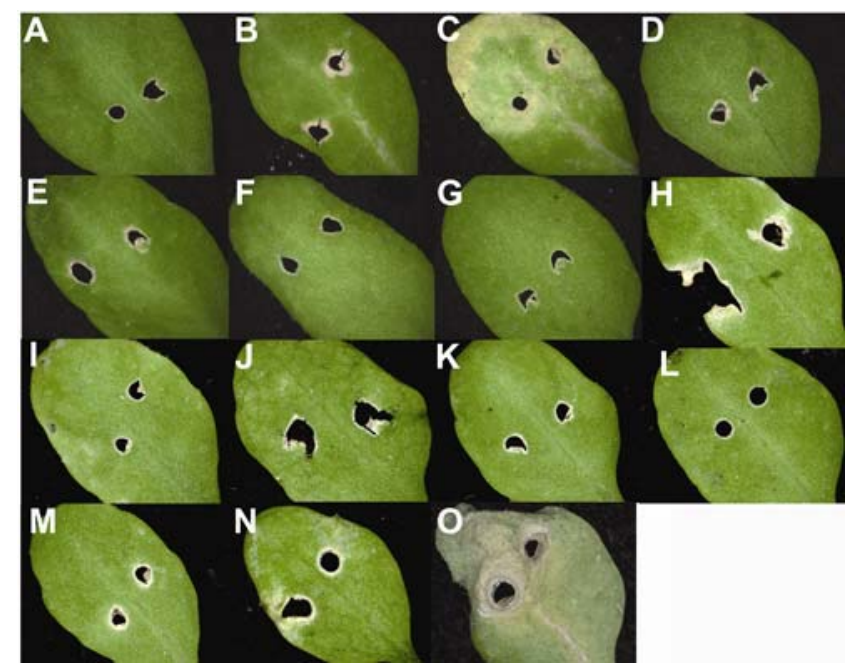

Fig. 1. Disease phenotypes on Ler-0 mutants compromised in abscisic acid (ABA) biosynthesis and signaling, 14 says postinoculation (dpi). The experiment was repeated twice, with 20 plants. A, Resistant phenotype on Ler-0. Susceptible phenotype on B, abal-3 and C, abil-1. Resistant phenotype on D, abi2-1; E, abi3-1; F, abi5-1; and G, Ws-0. H, Moderately susceptible phenotype on abil-1R1. Resistant phenotype on I, abil-1R2; $\mathbf{J}$, abil-1R3; K, abil-1R4; L, abil-1R5; and M, abi1-1R7. N, Moderately susceptible phenotype on abil-1R4abi2-1R26. $\mathbf{O}$, A hypersusceptible phenotype on lmslabil-1, 4 dpi. performed. Among a number of physiologically defined Arabidopsis mutants, the ABA-defective mutants of Ler-0 origin, abal-3 and abil-1, but not the insensitive mutants abi2-1, abi3-1, or abi5-1 (Ws-0 background) were found to be susceptible to L. maculans (Fig. 1A through G). $A B I 1$ and $A B I 2$ are two structurally and functionally homologous genes coding for protein-phosphatase 2C (PP2C) proteins. The abil-1 and abi21 mutations both affect an amino acid at the catalytic site, which results in a dominant phenotype (Leung et al. 1997). In order to confirm that the susceptible phenotype seen in the abil-1 mutant was due to the dominant negative activity, seven cognate suppressor lines (Gosti et al. 1999) were evaluated for L. maculans responses (Fig. 1H through N). Interestingly, only the abil-1Rl showed a moderate disease phenotype on some ( 5 of 36) leaves, whereas all other suppressor lines remained resistant. In contrast to the other suppressor lines, which show complete or near-complete loss of ABI1-1 phosphatase activity, abil-1Rl still shows $1.3 \%$ activity (Gosti et al. 1999) indicating that even a low ABI1-1 activity negatively influences $L$. maculans resistance. Weaker phenotypes on the remaining lines correlate with the phenotypic analyses presented by Gosti and associates (1999). Surprisingly, the abil-1R4abi2-1R26 double mutant showed susceptible phenotypes on a few (4 of 27) leaves, whereas abil-1R4 remained completely resistant. This implies that ABI1 and ABI2 may have opposite effects on L. maculans resistance. Expression patterns show that $A B I 3$ and $A B I 5$ are expressed only in seed, indicating that those genes have little effect on adult leaf ABA responses (Schmid et al. 2005).

\section{Camalexin-free background confirms ABA requirement for $L$. maculans resistance in Col-0.}

ABA-impaired mutants in Col-0 background (aba2-1, aba3-1, and $a b i 4-1$ ), in contrast to mutants in Ler-0 background, did not display any disease symptoms (Fig. 2A through D). Col-0 expresses approximately three times higher levels of the phytoalexin camalexin compared with Ler-0 and Ws-0, a defense component which can interfere with susceptibility assessments (Staal et al. 2006). No difference in camalexin induction between susceptible ABA mutants and resistant genotypes of Ler-0 background could be found (data not shown). In order to further evaluate the role of $\mathrm{ABA}$, double mutants between the

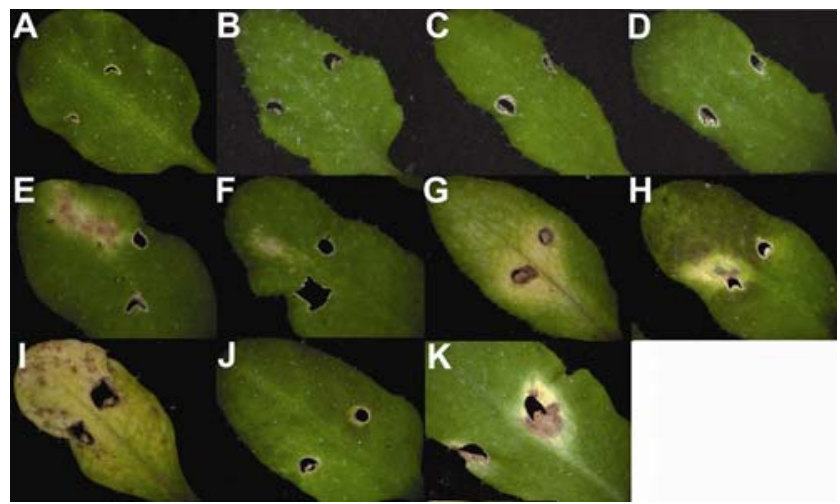

Fig. 2. Disease phenotypes on Col- 0 mutants compromised in abscisic acid (ABA) biosynthesis and signaling. Disease phenotypes against Leptosphaeria maculans are unveiled on mutants in Col-0 background when crossed to the camalexin-deficient mutant pad3-1. The experiment was repeated twice with 20 plants. Resistant phenotype on A, Col-0; B, aba2-1; C, aba3-1; and D, abi4-1, 14 dpi. Disease development on E, aba2pad3 and $\mathbf{F}$, aba3pad3, 11 days postinoculation (dpi). G, Clear lesion phenotype on the abi4pad3 double mutant, 11 dpi. Susceptible phenotype on $\mathbf{H}$, pmr4pad3 and I, $\operatorname{rlm} 1_{\mathrm{Ler}}$ pad3, $11 \mathrm{dpi}$. J, No visible disease lesions on the pad3-1 background genotype, 11 dpi. K, The mutant pad3-1 started to display clear lesions $15 \mathrm{dpi}$. 
camalexin-deficient pad3-1 and aba2-1, and aba3-1 and abi4-1 were made. The responses of those genotypes (Fig. 2E through G) were compared with pmr4pad3 and $r \operatorname{lm} 1_{\text {Ler }}$ pad3 (Fig. 2H and I), a hypersusceptible double mutant deriving from pad3-1 $\left(R L M 1_{\mathrm{Col}} r l m 2_{\mathrm{Col}}\right)$, and a Col-0 $\times$ Ler-0 line $\left(r \operatorname{lm} 1_{\mathrm{Ler}} r \operatorname{lm} 2_{\mathrm{Col}}\right)$, which has lost the $R L M 1_{\mathrm{Col}}$ allele and its putative paralog $R L M 2_{\mathrm{L} e r}$ due to transgressive segregation (Staal et al. 2006). Disease severity 11 days postinoculation showed that $r \operatorname{lm} 1_{\text {Ler }}$ pad3 was clearly more susceptible than pmr4pad3 (Fig. $2 \mathrm{H}$ and $\mathrm{I}$ ), indicating that $R L M 1$-dependent resistance is controlled by additional components independent of callose deposition. The double mutants aba2pad3, aba3pad3, and abi4pad3 all displayed an enhanced L. maculans susceptibility (Fig. 2E through G), which shows that all steps in the ABA biosynthesis are important for $L$. maculans resistance. ABAdependent resistance against $L$. maculans also is regulated by a more extensive response than enhancement of callose deposition, because the abi4pad3 double mutant displayed a clearly more severe disease phenotype compared with pmr4pad3, even if the emergence of lesions was earlier in pmr4pad3 than in abi4pad3. In contrast to $A B I 3$ and $A B I 5$, expression of the Apetala2 (AP2) domain transcription factor $A B I 4$ can be found throughout the whole plant (Schmid et al. 2005). ABI4 previously has been shown to be involved in both BABA-induced sterility and BABA-induced resistance to A. brassicicola and Plectosphaerella cucumerina by the priming of callose depositions (Ton and Mauch-Mani 2004; Ton et al. 2005). Interestingly, the abil-1 mutation, but not abi2-1, severely reduces $A B I 4$ expression (Söderman et al. 2000), which might explain the differences between the two PP2C mutants in L. maculans responses. The pad3-1 background had not developed any visible disease symptoms at 11 days postinoculation (Fig. 2J) and started to show the first clear lesions at 15 days postinoculation (Fig. 2K). Thus, the single pad3-1 mutant exposes a 4- to 5-day delay in symptom development compared with the double mutants. Furthermore, quantitative disease progression assessments in $\mathrm{F}_{3}$ of the aba2-1, aba3-1, abi4-1, and pmr4 mutants in pad3-1 background compared with $r \operatorname{lm} 1_{\text {Ler }}$ pad3 and pad3-1 confirmed partial loss of $R L M 1$ resistance.

\section{Secondary messenger mutants reveal $\mathrm{H}_{2} \mathrm{O}_{2}$ dependency of $\boldsymbol{L}$. maculans resistance.}

One common denominator between pathogen responses and ABA signaling is the NADPH oxidase-dependent generation of $\mathrm{H}_{2} \mathrm{O}_{2}$ (Kwak et al. 2003; Torres et al. 2002, 2005). Evaluation of the respiratory burst NADPH-oxidase rbohD and $r b o h F$ mutants revealed only moderate susceptible responses, whereas the double mutant $r b o h D F$ showed a hypersusceptible response to L. maculans (Fig. 3A through C). Another secondary messenger important for both ABA and pathogen responses is nitric oxide (NO), which can be generated either via nitrate reductase in an $\mathrm{H}_{2} \mathrm{O}_{2}$-dependent manner or via nitric oxide synthase (Bright et al. 2006). In order to test the influence of NO, mutants in the two pathways impaired in some ABA responses were evaluated. The nitrate reductase-deficient double mutant nialnia2 (nitrate reductase 1 nitrate reductase 2) showed moderate susceptible phenotype, whereas the Atnos1 (nitric oxide synthase 1) mutant remained resistant (Fig. 3D and E). In conclusion, reactive oxygen species (ROS)-generated signals and ABA play an important role in L. maculans responses. However, the $i b s 2$ (impaired in BABA-induced sterility 2) mutant impaired in BABAinduced sterility and defective in phosphoinositol signaling, which represents a pathway parallel to $\mathrm{ABA}$ for BABAprimed callose depositions (Ton et al. 2005), remained as resistant as the wild type (Fig. 3F).
ABA and BABA pretreatment induces resistance in Arabidopsis and oilseed rape.

ABA and BABA have been shown to induce resistance against different fungal pathogens in Arabidopsis (Jakab et al. 2001). This knowledge and the fact that some ABA mutants showed susceptibility against $L$. maculans led to experiments with ABA and BABA treatments. Application via drenching of the soil with BABA at $16 \mathrm{mg} / \mathrm{liter} 2$ days preinoculation caused a significant induction of resistance in the susceptible Arabidopsis mutants abal-3, pad3-1, pmr4-1 esal, and pen1 (Fig. 4A through E). However, the Arabidopsis genotypes abil-1 and $r l m 1_{\mathrm{Ler}}$ pad3-1 and the L. maculans-susceptible $\operatorname{lms} 1$ and $r \operatorname{lm} 1_{\mathrm{Ler}} r \operatorname{lm} 2_{\mathrm{Col}}$ did not display any resistance due to the treatments (Fig. 4F through I) compared with the resistant wild-type Col-0 (Fig. 4J).

In order to avoid induced senescence, causing loss of potentially diseased leaves at an early stage, ABA pretreatments with $25 \mu \mathrm{M}$ ABA 2 days before and 3 days after inoculation were performed instead of pretreatments using $80 \mu \mathrm{M}$ ABA (Ton and Mauch-Mani 2004). The lower concentration of ABA resulted in an induction of resistance in the susceptible Arabidopsis mutants abal-3, pad3-1, and pmr4-1 (Fig. 4A throuigh C), but also in the enhanced susceptibility mutant esal and the papilla formation mutant pen1 (Fig. 4D and E). However, as in the case of BABA pretreatment, the Arabidopsis mutants abil1 (Fig. 4F) and the L. maculans-susceptible lms 1 (Fig. 4H) did not show any induced resistance. In order to see whether Ims I and abil-1 reside in the same signaling pathway, as suggested by the lack of restoration by ABA and BABA, an lmslabil double mutant was generated. The double mutant did show a hypersusceptible phenotype with lesions emerging already at 4 days postinduction (dpi) (Fig. 1O). However, no defects in callose deposition could be seen in the lms 1 mutant (data not shown). The epitasis between $l m s 1$ and abil-1 shows that these two mutants represent two parallel pathways of central importance for $L$. maculans resistance. The additive effects seen in the lmslabil-1 double mutant could be analogous to previous reports on interactions between ET mutants and abil-1 (Fedoroff 2002), because the lms1 mutant shows an ET-insensitive root and enhanced sensitivity to ET in the shoot (Bohman et al. 2004). The lms 1 mutant also shows glucose-insensitive germination (data not shown), a well-known cross-talk between ABA and ET (Fedoroff, 2002). The genotypes $r \operatorname{lm} 1_{\text {Lerp }}$ pad3 (Fig. 4G) and $r \operatorname{lm} 1_{\mathrm{Ler}} r \operatorname{lm} 2_{\mathrm{Col}}$ (Fig. 4I) both displayed partial restoration of resistance after ABA treatment, which demonstrates that $\mathrm{ABA}$ acts as a signal downstream of $R L M 1_{\mathrm{Col}}$.

To evaluate whether the induced resistance response found in Arabidopsis is effective in oilseed rape, three genotypes (the

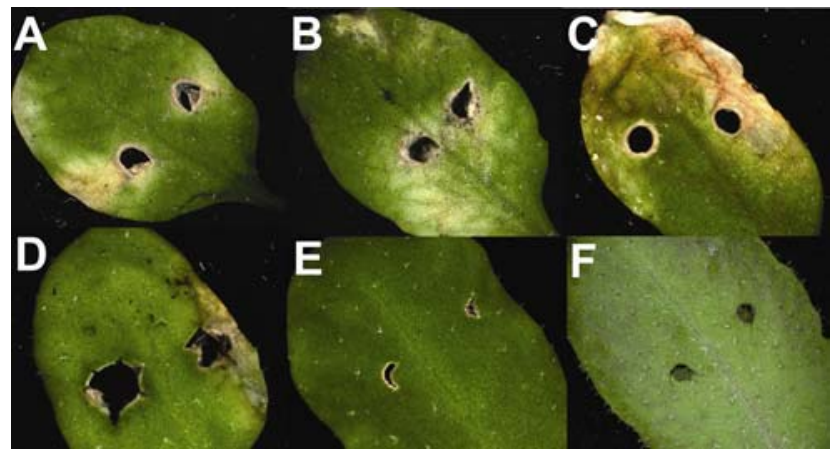

Fig. 3. Disease phenotypes on secondary messenger mutants, 14 days postinoculation (dpi). The experiment was repeated twice with 20 plants. Susceptible phenotype on $\mathbf{A}, r b o h D$ and $\mathbf{B}, r b o h F$. C, Hypersusceptible phenotype on rbohDF, $7 \mathrm{dpi}$. D, Susceptible phenotype on nialnia2. Resistant phenotype on E, Atnos 1 and $\mathbf{F}, i b s 2$. 

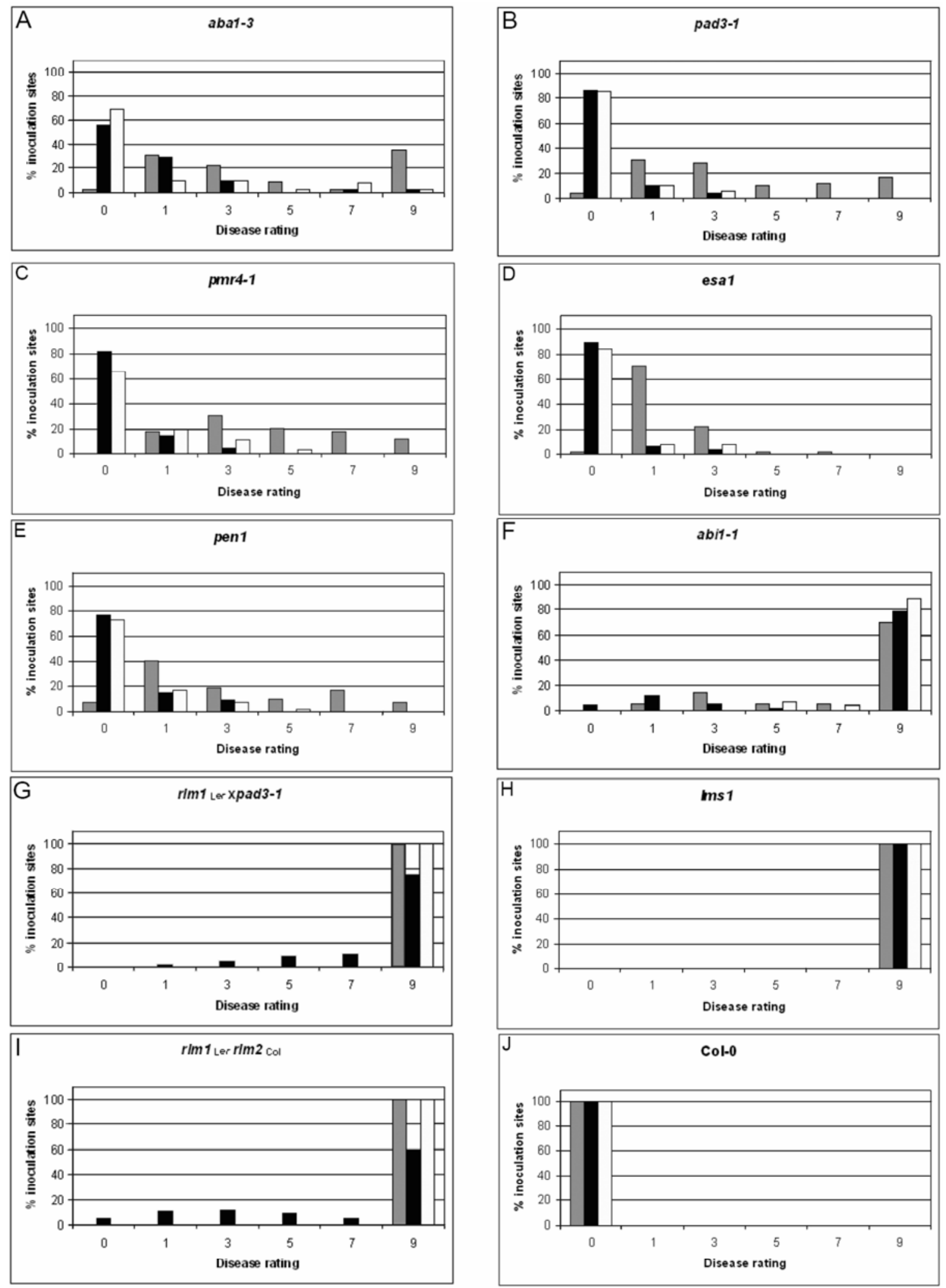

\section{$\square$ Water pretreatment $\square$ ABA pretreatment $\square$ BABA pretreatment}

Fig. 4. Defense scoring after abscisic acid (ABA) and $\beta$-aminobutyric acid (BABA) pretreatments on Arabidopsis mutants, 21 days postinoculation (dpi). The plants were soil drenched with water and BABA at $16 \mathrm{mg} /$ liter 2 days prior to infection or pretreated with $25 \mu \mathrm{M}$ ABA 2 days before inoculation and 3 dpi. After inoculation with Leptosphaeria maculans, the disease symptoms were scored every second day according to Delwiche and Williams (1979): $0=$ no symptoms; 1 = lesion diameter 0.5 to $1.5 \mathrm{~mm} ; 3=$ dark necrotic lesions 1.5 to $3 \mathrm{~mm} ; 5=$ lesions 3 to $5 \mathrm{~mm}$, occasional sporulation; and $7=$ gray-green tissue collapse, lesions 4 to $8 \mathrm{~mm}$, sporulation. The values (\%) presented were based on the total number of inoculation sites. The scale on the $\mathrm{x}$-axis refers to the disease scoring scale. A, abal-3; B, pad3-1; C, pmr4-1; D, esal; E, penl; F, abil-1; G, $r \operatorname{lm} 1_{\mathrm{Ler}} p a d 3-1 ; \mathbf{H}, \operatorname{lms} 1 ; \mathbf{I}, r \operatorname{lm} 1_{\mathrm{Ler}} r \operatorname{lm} 2_{\mathrm{Col}}$; and J, Col-0, 21 dpi. The experiment was repeated twice (10 plants and 50 to 60 inoculation sites were used for each genotype and treatment) and the standard deviation (SD) varied between 1.4 and 26.0, with a mean of 99 and 81.6, respectively. 
susceptible B. napus cv. Hanna, nahG in Hanna background, and the resistant cv. Surpass 400) harboring the single dominant L. maculans resistance gene LepR3 (Li and Cowling 2003) were treated with $\mathrm{BABA}$ and $\mathrm{ABA}$ as described above prior to inoculation with $L$. maculans. A significant induction of resistance in the two susceptible genotypes was observed after $\mathrm{BABA}$ pretreatment, demonstrating that BABA induces resistance independently of SA against $L$. maculans. ABA pretreatment also resulted in an unambiguous induction of resistance.

Furthermore, to assess whether BABA treatment influences ABA biosynthesis, endogenous levels of ABA were determined using gas chromatography/mass spectrometry (GC/MS) for whole-leaf analysis and enzyme-linked immunosorbent assay (ELISA) for local ABA induction analysis. BABAtreated and fungal-inoculated Ler-0 plants demonstrated a clear enhancement (1.5 times) of ABA levels compared with the water-inoculated control 3 dpi $(P<0.003)$, which shows that ABA is pathogen induced. The water-inoculated BABApretreated plants displayed ABA levels comparable to Ler-0 without BABA treatment. ELISA measurements of local ABA induction showed the same pattern with an earlier peak induction (1 dpi) after L. maculans or wounding (data not shown).

\section{Transcriptional analysis reveals an enhanced SA response in susceptible ABA mutants.}

Defense-related gene expression in the contrasting ABA mutants was analyzed. After inoculation, the susceptible Ler-0 genotypes abal-3 and abil-1 expressed an enhanced $P R-1$ induction, whereas the resistant mutant abi2-1 had a $P R-1$ induction comparable with the wild type (Fig. 5). BGL2 (PR2) was moderately expressed in all genotypes except abil-1, where a clear induction after $L$. maculans challenge could be seen. The two susceptible mutants (abal-3 and abil-1) influenced the PDF1.2 expression differently, where abil-1 had an enhanced PDF1.2 expression; whereas abal-3 and abi2-1 showed reduced PDF1.2 expression compared with the wild type (Fig. 5). The JA-induced VSP2 showed no difference between mock-inoculated and L. maculans-inoculated materials at 48 hours postinoculation (hpi). However, the wound induction of VSP2 clearly was enhanced in abil-1 compared with the other genotypes (Fig. 5). No significant shift of callose synthase (GSL5) expression was detected in the different ABA mutants, independent of challenges, which is in agreement

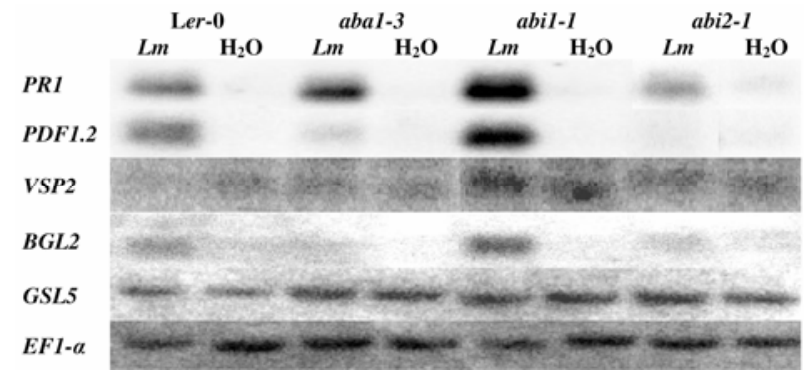

Fig. 5. Expression patterns of defense-related genes in Arabidopsis genotypes. Northern analysis of Ler-0, abal-3, abil-1, and abi2-1, $48 \mathrm{~h}$ postinoculation with Leptosphaeria maculans $(\mathrm{Lm})$ and water. All genotypes expressed the salicylic acid-responsive gene $P R-1$, and the susceptible genotypes abal-3 and abil-1 exhibited higher expression compared with the resistant genotypes Ler-0 and abi2-1. Expression of the jasmonic acid and ethylene (JA/ET)-responsive gene PDF1.2 did not correspond to susceptibility, whereas the mutants abal-3 and abi2-1 had reduced PDF1.2 gene expression. The JA-responsive gene VSP2 did not express differently between treatments, but abil-1 showed enhanced VSP2 expression compared with the other genotypes. The callose synthase GSL5 did not vary in expression between treatments or genotypes. The experiment was repeated twice with the same expression pattern. with data in the transcription profile database Genevestigator (Zimmermann et al. 2004). Taken together, the ABA mutants affect the expression of SA-, JA-, and JA-ET-dependent defenses after L. maculans challenge differently and susceptible genotypes appear to have an enhanced SA response.

\section{Callose deposition only partially explains L. maculans resistance.}

To evaluate whether the ABA- and BABA-induced resistance was due to altered callose deposition, aniline blue staining was performed (Gressel et al. 2002). The staining of leaves from Arabidopsis mutants after pretreatments revealed that both abil1 and abal-3 had significant differences $(P \leq 0.01)$ in callose densities compared with Ler-0, whereas the differences were minor in abi2-1 (Fig. 6A). The analysis of callose depositions in pad3 in Col-0 background $\left(\left(R L M 1_{\mathrm{Col}}\right)\right.$ pad3) and $r l m 1_{\mathrm{Ler}}$ pad3 after ABA and BABA pretreatment revealed that callose deposition is enhanced in $R L M 1_{\mathrm{Col}}$ plants, whereas callose deposition in $r l m 1_{\mathrm{Ler}}$ plants is not affected by pretreatments (Fig. 6B). The dependency of $R L M 1_{\mathrm{Col}}$ for callose deposition shows that $\mathrm{ABA}$ and BABA enhances deposition downstream of this induction. The callose synthase mutant pmr4-1 displayed low levels of callose under all pretreatment conditions (Fig. 6B), but still exhib-

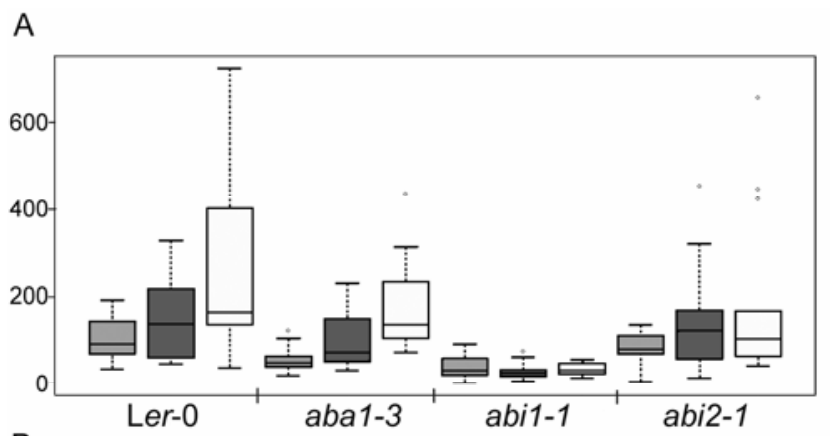

B

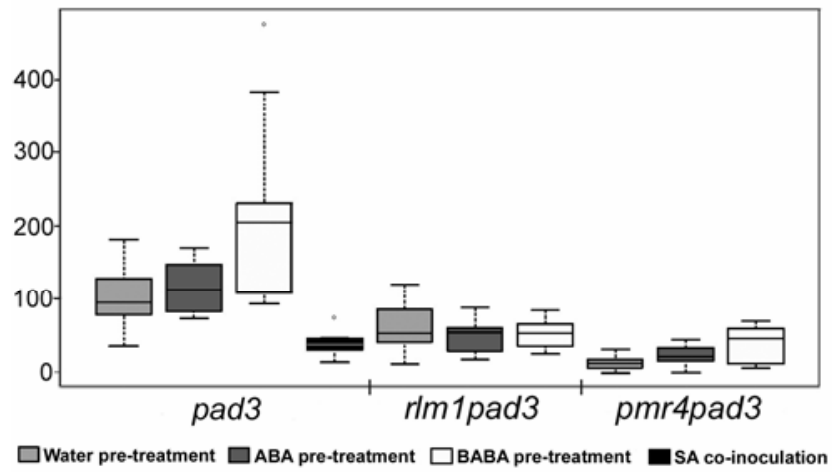

Fig. 6. Callose deposition determined via aniline blue-stained leaves of $\beta$ aminobutyric acid (BABA) and abscisic acid (ABA) pretreated Arabidopsis mutants. The extent of callose deposition in response to Leptosphaeria maculans inoculation was evaluated over time. When the first true leaves were developed, the plants were treated by soil drench with water, ABA, or BABA 2 days prior to inoculation with $L$. maculans. The staining was performed 2 days postinoculation. Box plot representation of the quantification of callose depositions in inoculated leaves for each genotype was expressed as a percentage of the average background levels (Col- 0 and Ler-0). The box plot was made using the 'boxplot()' function in R (R Foundation for Statistical Computing, Vienna, Austria). The middle bar represents the average value, boxes the value range of the first quartiles over and under average ( $50 \%$ of measured values), and the bars represent the value range of the two outer quartiles. A, Ler-0, abal-3, abil-1, and abi2-1 in Ler-0 background; B, pad3, $r \operatorname{lm} 1_{\mathrm{Ler}}$ pad3, and pmr4-1pad3 in Col-0 background. The pmr4 single mutant has the same callose deposition as the pmr4pad 3 double mutant. The scale on the $\mathrm{y}$-axis refers to the relative callose deposition density, expressed as percentage of water-pretreated wild type. The experiment was repeated twice with 10 biological replicates. 
ited a clear enhanced resistance after $\mathrm{ABA}$ and BABA pretreatments (Fig. 4C). This observation clearly demonstrates that ABA-induced resistance is a complex response and comprises other factors than the enhancement of callose depositions. To investigate whether SA-derived signals affect callose deposition, pad3-1 plants were inoculated with an L. maculans spore solution together with $50 \mu \mathrm{M}$ SA. The latter is an additive which does not influence the spore germination and growth of $L$. maculans. Plants co-inoculated with SA and L. maculans displayed a severely reduced callose deposition compared with plants only inoculated with L. maculans (Fig. 6B).

To compare our findings from Arabidopsis, staining for callose deposition also was carried out on B. napus leaves from plants pretreated with water, ABA, and BABA 2 dpi (Fig. 7). In agreement with our observations on $R L M 1_{\mathrm{Col}}$ and $r l m 1_{\mathrm{Ler}} r l m 2$ Arabidopsis genotypes, the resistant B. napus cv. Surpass 400 exhibited enhanced levels of callose deposition after pathogen challenge when compared with the susceptible cv. Hanna upon fungal inoculation (Fig. 7). However, when ABA and BABA pretreated cv. Hanna plants were analyzed, the callose levels were comparable to Surpass 400 (Fig. 7). Staining of leaves inoculated with water showed no callose deposition, demonstrating that the callose observed was exclusively pathogen induced. In order to evaluate whether the callose production was SA dependent, as described by Donofrio and Delaney (2001), the B. napus cv. Hanna $n a h G$ genotype was assessed in a similar manner. No significant differences were found between $n a h G$ plants and the wild type, except a slightly enhanced callose deposition in $n a h G$ in the water-pretreated samples (Fig. 7).

\section{Global transcription analysis reveals} differentially regulated genes between the susceptible abil-1 and resistant abi2-1 mutants.

Despite the molecular similarities between abil-1 and abi21 , the two mutants show drastic differences in L. maculans

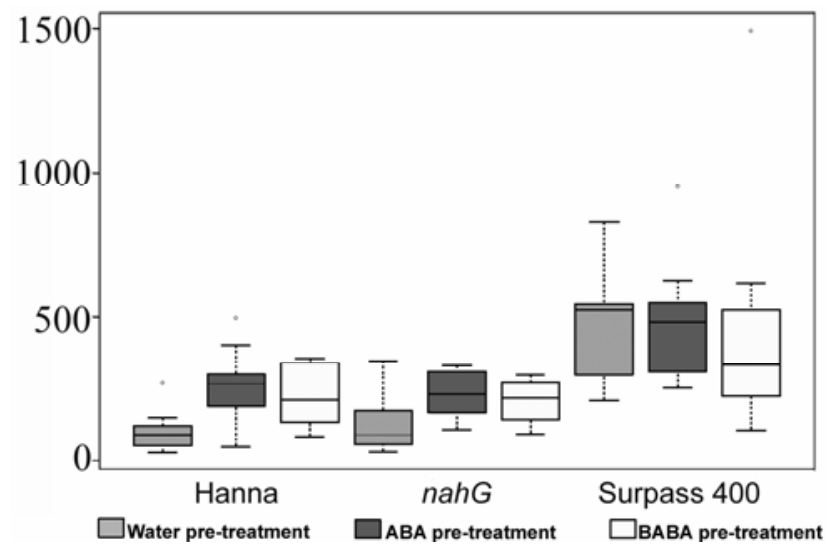

Fig. 7. Callose quantification in abscisic acid (ABA)- and $\beta$-aminobutyric acid (BABA)- pretreated Brassica napus genotypes. Box plot representation of the quantification of callose depositions in inoculated leaves of Hanna, $n a h G$ in Hanna background, and Surpass 400 was expressed as a percentage of the average water-pretreated Hanna levels. When the first true leaves were developed, the plants were treated by soil drench with ABA or BABA 2 days prior to inoculation with Leptosphaeria maculans. The staining was performed 2 days postinoculation. The box plot was made using the 'boxplot()' function in R (R Foundation for Statistical Computing, Vienna, Austria). Middle bar represents average value, boxes the value range of the first quartiles over and under average (50\% of measured values), and the bars the value range of the two outer quartiles. Boxplot of callose content measured on 8 to 10 individual leaves per treatment and genotype using the program APS assess. The scale on the y-axis refers to the relative callose deposition density expressed as a percentage of water-pretreated Hanna. The experiment was repeated twice with 10 biological replicates. responses. In order to identify the subset of $\mathrm{ABA}$ responses influenced by $\mathrm{ABI} 1$, but not by $\mathrm{ABI} 2$, required for resistance a microarray comparison between the two mutants was performed after ABA pretreatment and L. maculans inoculation. Microarray analysis revealed 74 genes to be differentially expressed $(B>1, P<0.1)$ between the resistant abi2-1 and the susceptible abil-1 mutants 2 dpi. An interesting observation is that the RLM1-related gene At1g63870 is more highly expressed in abi2-1, which may indicate that $\mathrm{ABI} 1$ modulates $R L M 1_{\mathrm{Col}}$ accumulation after $L$. maculans stress. To investigate whether this was the case, quantitative polymerase chain reaction (PCR) analyses were made on abil-1 and abi2-1 array samples for the homologous TIR-NB-LRR genes in the RLM1 locus. Assessments of most genes were inconclusive; however, At1g63750 showed a $32 \%$ higher expression $(P<0.04)$ in abi2-1 compared with abil-1. Because both abil-1 and abi2-1 are of Ler-0 background and, thus, only have a functional RLM2 locus (Staal et al. 2006), we also compared four pools of pad3-1 and abi4pad3 in Col-0 background 2 dpi for evaluations of genotypes with a functional RLM1 locus. Contrary to our expectations, At1g63870 $(P=0.002)$ and At1g64070 $(P=$ 0.014 ) was approximately twofold upregulated in abi4pad3 compared with pad3, whereas At1g63880 expression remained constant (Fig. 8). We interpret this as there being an ABI1-dependent feedback upstream of ABI4 that negatively regulates RLMI expression. ABI1 activity, in turn, could be feedback regulated by ABA responses downstream of ABI4 (Merlot et al. 2001; Saez et al. 2004), which would reduce ABI1-dependent repression of RLM1 in an abi4 background. Supporting this hypothesis, Northern blot data of $A B I 1$ in the four pad3-1 and the four abi4pad3 RNA pools revealed a 1.7-fold decrease on average $(P=0.06)$ of $A B I 1$ transcripts in the abi4 background (data not shown).

\section{DISCUSSION}

\section{Common features}

in pathogen responses and $\mathrm{ABA}$ signaling.

Previously, ABA has been associated almost exclusively with deleterious effects on plant defense responses; however, an increasing number of reports show that there are cases where ABA acts as a positive regulator of resistance (Flors et al. 2005). The present reports, however, do not show a requirement for endogenous ABA for resistance. A reduction of the

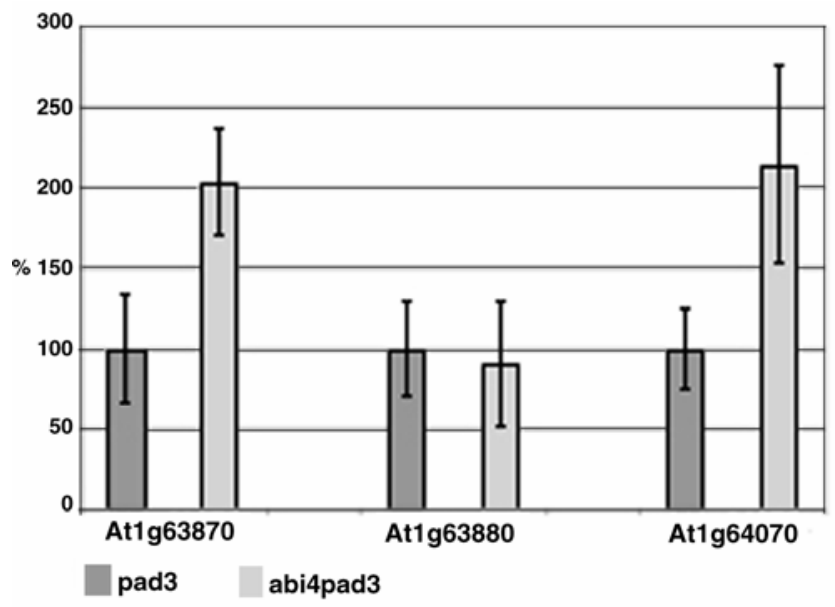

Fig. 8. Quantitative polymerase chain reaction (PCR) analysis of $R L M 1$ related genes in pad3 and abi4pad3. Quantitative measurements of At1g63870, At1g63880, and At1g64070 in pad3 and abi4pad3 determined by real-time PCR, $48 \mathrm{~h}$ postinoculation. The experiment was repeated twice with four biological replicates. 
endogenous ABA has been reported to cause increased resistance, whereas positive influences from $\mathrm{ABA}$ on resistance have been found after exogenous application (Ton and MauchMani 2004). In the case of L. maculans, endogenous ABA and a functional ABA signaling via $\mathrm{ABI} 1$ and $\mathrm{ABI} 4$ is required to maintain $R L M 1_{\mathrm{Col}^{-}}$and $R L M 2_{\mathrm{Ler}}$-dependent resistance. The most apparently susceptible phenotype to $L$. maculans among ABA mutants was visible on the dominant negative PP2C mutant, abil-1. The abi2-1 mutation with similar effects on a homologous gene (Leung et al. 1997) lacked this distinct response, suggesting differential modes of action. Earlier transcriptional profiling has revealed that only $9 \%$ of the ABA-responsive genes are abil-1 independent (Hoth et al. 2002). In addition, a number of potentially important genes for plant pathogen defense were shown to be both positively and negatively regulated by ABA application in an abil-1-dependent manner (Hoth et al. 2002). It has been proposed that abi2-1 has a less severe impact on the Arabidopsis transcriptome compared with abil-1 (Xiong et al. 2002). This may be due, in part, to a repression in abil-1, but not in abi2-1, of zeaxantin epoxidase $(A B A 1)$ which is important for ABA biosynthesis. The abil-1 mutant also has been found to impair the activated disease resistance gene $A D R 1$ (coiled coil-NB-LRR), which also confers SA- and EDS1-dependent drought resistance (Chini et al. 2004), thus linking ABI1 activity to the NB-LRR class of pathogen resistance genes. The induction of disease response-like lesions under low humidity stress in the sensitive to low humidity 1 (slhl) mutant in a gene conferring resistance to Ralstonia solanacearum (TIR-NB-LRR-WRKY) is yet another connection between ABA responses and the activity of NBLRR-type resistance genes (Noutoshi et al. 2005). Another lesion mimic mutant, lesion simulating disease 1 ( $l s d l$ ), induces an EDS1 and PAD4-dependent hypersensitive-response-like cell death associated with stomata regulation and photorespiration, further emphasizing the link between ABA-regulated responses and the TIR-NB-LRR resistance responses (Mateo et al. 2004).

The induction of ROS also might be an important connection between $\mathrm{ABA}$ and pathogen responses, because the formation of the secondary messenger hydrogen peroxide is dependent on superoxide via the NADPH oxidases RbohD and RbohF (Kwak et al. 2003; Torres and Dangl 2005; Torres et al. 2002). NADPH oxidases also may function as negative regulators of cell death (Torres et al. 2005), which might be the cause of the hypersusceptible phenotype observed in the RbohDF double mutant. Furthermore, NO is a central player in both ABA activity (Desikan et al. 2002) and the induction of SA defenses (Klessig et al. 2000). The origin of NO has been widely disputed and two pathways, either via nitrate reductase (Desikan et al. 2002) or through a nitric oxide synthase (Guo et al. 2003), based on genetic, pharmacological, and physiological evidence, have been demonstrated to be of central importance for intact ABA signaling activity. The two NO pathways appear to be activated in different contexts, where the nitrate reductase-dependent generation of $\mathrm{NO}$ relies on $\mathrm{H}_{2} \mathrm{O}_{2}$ from the NADPH oxidases RbohD and RbohF (Bright et al. 2006). There also may be convergences between ABA signaling events and plant defense in ROS-elicited oscillations of cytosolic $\mathrm{Ca}^{2+}$ (Klüsener et al. 2002). The closing of stomata, which per se can serve as entrance for some pathogens such as L. maculans (Chen and Howlett 1996), also may be a common denominator in plant disease resistance and ABA responses. However, regulation of stomatal closure as a mechanism of ABA-induced resistance is not a likely explanation for our infection experiments, because we caused a wound for entrance of L. maculans into the leaf as part of the inoculation procedure.
The positive impact of $\mathrm{ABA}$ on resistance to A. brassicicola and $P$. cucumerina was established through the requirement for ABA in SA-independent and callose-dependent cases of BABA-IR (Ton and Mauch-Mani 2004). BABA-IR against $L$. maculans in B. napus is clearly an SA-independent process. The slight enhancement of susceptibility observed in both water- and BABA-pretreated B. napus plants harboring the $n a h G$ gene could possibly be attributed to a detrimental effect of catechol on resistance, because catechol can induce inappropriate levels of hydrogen peroxide and probably accelerates cell death (van Wees and Glazebrook 2003), which is beneficial for L. maculans (Bohman et al. 2004). Our results show that ABA has a wider activity than described by Ton and Mauch-Mani (2004), because we also obtain a clear induction of resistance in a callose-deficient background.

\section{Callose-independent $\mathrm{ABA}$-induced resistance responses.}

Genes differentially affected by the two PP2C isoforms are shown in microarray comparisons between abil-1 and abi2-1. Several transcription factor gene families are differentially induced in both genotypes, suggesting that control of several genes is differentially regulated by the two PP2C proteins when challenged by L. maculans. The documented differential regulation of $A B I 4$ in the two mutants (Söderman et al. 2000) is of particular interest in this context. Additional support for the differential roles of $\mathrm{ABI} 1$ and $\mathrm{ABI} 2$ is given by the recent results, which show that abil-1 and abi2-1 have opposite effects on the expression of lipid-binding proteins involved in photosystem II inhibition under abiotic stress (Yang et al. 2006). In the case of L. maculans resistance, one major influence could be the ABI1-dependent repression of RLMI and $R L M 1$-like genes, which could act as a feedback loop to modulate $R L M 1$ expression after infection. This feedback occurs upstream of ABI4, which also could explain the less severe phenotype observed on abi4-1 compared with abil-1.

\section{Cross-talk between ABA and \\ other pathogen resistance hormones.}

Our expression analysis of resistant and susceptible genotypes of Ler-0 background showed higher SA-dependent responses in the susceptible genotypes. Furthermore, the reduced callose deposition after co-inoculation with $L$. maculans and SA and the slightly enhanced callose levels in nahG B. napus compared with wild-type $B$. napus indicates that repression of SA responses may be part of the ABA-dependent resistance response. The callose synthesis gene GSL5 did not show any alterations in any of the genotypes or differences between inoculated and control material. This indicates that callose deposition is not regulated via transcription of GSL5, but could be influenced by multiple downstream events such as post-translational modifications of GSL5, subcellular localization, substrate availability, and callose degradation via $\beta$-1,3-glucanases. $\mathrm{ABA}$ is known to repress both SA- and JA-dependent resistance responses (Anderson et al. 2004; Audenaert et al. 2002; McDonald and Cahill 1999; Mohr and Cahill 2003; Rezzonico et al. 1998; Thaler and Bostock 2004), which might explain why both responses are enhanced in the abil-1 mutant. An alternative explanation of the higher pathogenesis-related (PR) gene expression in susceptible materials is that a successful colonization of the susceptible genotypes causes a higher stress, which in turn induces higher PR gene expression. A similar interpretation of the majority of the differentially expressed genes detected on the microarray comparison between $a b i 1-1$ and abi2-1 also could be valid.

\section{ABA acts downstream of RLM1 $1_{\text {Col }}$.}

The Arabidopsis-L. maculans responses found in this study show remarkable analogy to what has been reported previously 
for viral responses in tobacco. We observed an induction of ABA specifically after $L$. maculans challenge and we can induce resistance by application of $\mathrm{ABA}$, in a similar manner to that seen in the tobacco-Tobacco mosaic virus system (Whenham et al. 1986). The same is true for the ABA-dependent repression of callases and the enhancement of callose deposition after ABA treatment (Beffa et al. 1996; Rezzonico et al. 1998). Furthermore, callose was discovered to be partially responsible for resistance to L. maculans, but ABA also influenced other resistance responses. Based on observations of the enhanced susceptibility on mutants impaired in ABA biosynthesis and sensitivity, we concluded that the ABAinduced resistance is linked with endogenous ABA levels, and not only via exogenous application. Together with the observation of pathogen induction of ABA and complementation of resistance by exogenous $\mathrm{ABA}$ application to $r \operatorname{lm} 1_{\mathrm{Ler}}$ pad3 and $r l m 1_{\mathrm{Ler}} r l m 2_{\mathrm{Col}}$ genotypes, it was demonstrated that ABA acts downstream of $R L M 1_{\mathrm{Col}}$ (Fig. 9). BABA-IR required the function of $R L M 1_{\mathrm{Col}}$ for elevated ABA biosynthesis, whereas BABA also enhances the sensitivity to ABA and affects the ABA homeostasis in the plant, presumably via a feedback loop.

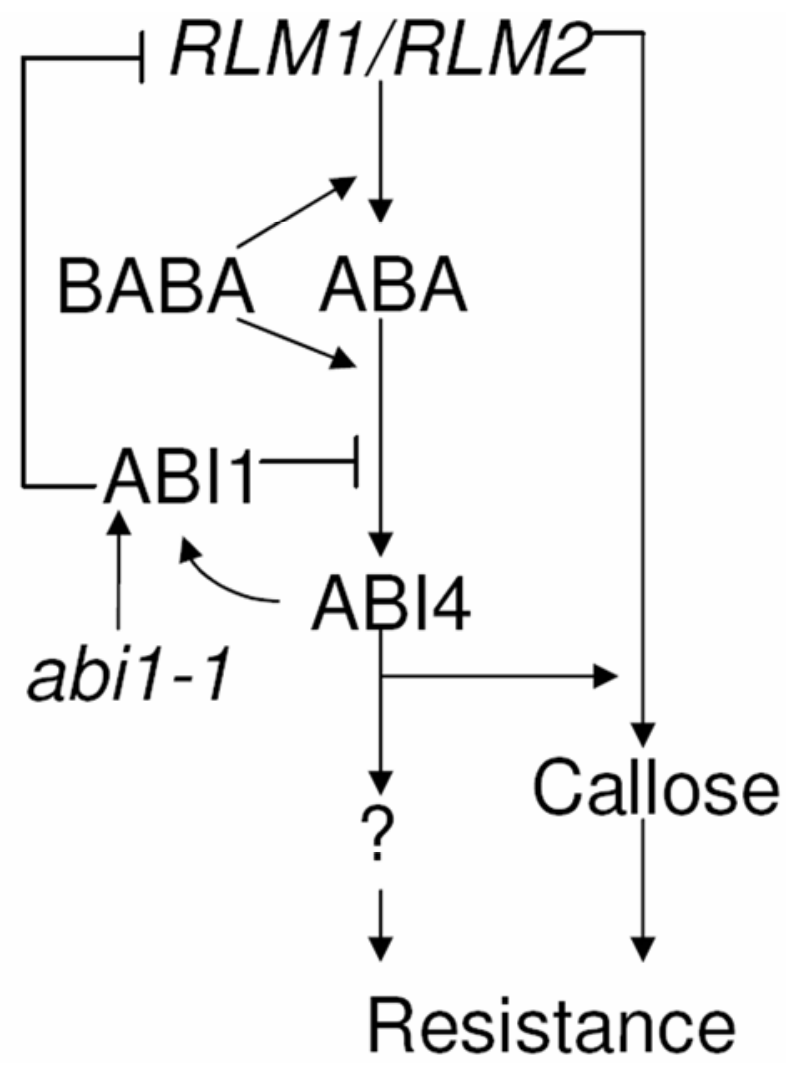

Fig. 9. Model for the role of abscisic acid (ABA) and $\beta$-aminobutyric acid (BABA) in Leptosphaeria maculans resistance. ABA is induced by pathogen recognition, which is enhanced by BABA pretreatment. BABA also activates defense responses downstream of ABA and enhances ABA sensitivity, but BABA cannot complement the absence of $R L M 1$ and $R L M 2$. That BABA acts both upstream and downstream of ABA indicates that it affects a feedback loop regulating ABA homeostasis. However, both ABA and BABA responses are blocked in abil-1 (this mutant has a constitutive ABI1-dependent repression of ABA responses) and abi4 mutants. Callose deposition is enhanced by ABA, but requires an $R L M 1$ signal because exogenously applied ABA is unable to complement lack of RLM1 in callose deposition. In addition to callose deposition, ABA induces a hitherto unknown resistance factor which can partially complement the absence of $R L M 1$. ABI1 is required for a pathogen-induced accumulation of $R L M 1$, but mutations in $A B I 4$ give opposite effects, suggesting that the feedback occurs upstream of ABI4 and that components downstream of ABI4 modulate ABI1 activity.
When ABA-insensitive mutants were assessed, only abil-1 and abi4-1 displayed susceptibility, whereas the other mutants (abi2-1, abi3-1, and abi5-1) remained resistant. This defines ABA-induced resistance to L. maculans as a subset of the ABA responses regulated via $\mathrm{ABI} 1$ and $\mathrm{ABI} 4$ and strongly suggests the presence of an unknown key resistance factor. A future challenge is to detect ABI4-induced genes and ABI4 binding promoters to further dissect this response.

\section{MATERIALS AND METHODS}

\section{Plant materials and culture conditions.}

Mutants of Arabidopsis used in this study have been described previously: abal-3 (Koornneef et al. 1982); aba2-1 and aba3-2 (Léon-Kloosterziel et al. 1996); abil-1, abi2-1, and abi3-1 (Koornneef et al. 1984); abi4-1 and abi5-1 (Finkelstein 1994); Atnos 1 (Guo et al. 2003); esal (Tierens et al. 2002); ibs2 (Ton et al. 2005); Ims1 (Bohman et al. 2004); nialnia2 (Desikan et al. 2002); pad3-1 (Glazebrook and Ausubel 1994); penl (Sanderfoot et al. 2000); pmr4-1 (Vogel and Somerville 2000); rbohD, rbohF, and rbohDF (Torres et al. 2002); and $r l m 1_{\mathrm{Ler}} r \operatorname{lm} 2_{\mathrm{Col}}, r l m 1_{\mathrm{Ler}} p a d 3-1$, and Ler-rlm2 $2_{\mathrm{Cvi}}$ (Staal et al. 2006). An Imslabil double mutant was generated for epitasis evaluations of the mechanisms for ABA- and BABA-insensitive susceptible phenotypes. Seven abil-1 suppressor lines, abil1R1, abil-1R2, abil-1R3, abil-1R4, abil-1R5, abil-1R4abi2$1 R 6$, and abil-1R7 (Gosti et al. 1999), were used to confirm the dominant-negative role of abil-1 for L. maculans responses. Columbia (Col-0), Landsberg erecta (Ler-0), and Wassilewskija (Ws-0) were used as controls in the experiments. The B. napus (L.) cv. Hanna, susceptible to L. maculans (Sjödin and Glimelius 1988), and Surpass 400, resistant to L. maculans (Li and Cowling 2003), were included for comparative studies.

The Arabidopsis material was cultured on sterilized soil for $8 \mathrm{~h}$ of light at $22^{\circ} \mathrm{C}$ and $16 \mathrm{~h}$ of darkness at $18^{\circ} \mathrm{C}$, with $65 \%$ humidity in growth chambers. The light intensity was 200 $\mu \mathrm{mol} \mathrm{m} \mathrm{m}^{-2}$. The humidity was raised to $100 \%$ the first $48 \mathrm{~h}$ after fungal inoculation to facilitate fungal growth. B. napus was cultured in the greenhouse under $16 \mathrm{~h}$ of light.

\section{Generation of transgenic B. napus.}

Hypocotyls of $B$. napus cv. Hanna were transformed with a binary construct harboring the $n a h G$ gene (Delaney et al. 1994). The transformation procedure was as described by Schröder and associates (1994) using streptomycin at $50 \mathrm{mg} / \mathrm{liter}$ in the selection step. Out of 24 primary transformants, lines with a single TDNA insert were selected based on segregation on streptomycin plates and Southern and Northern blotting.

\section{Inoculation of plant material.}

The responses to L. maculans were determined on Arabidopsis rosette leaves, at the five- to eight-leaf stage, by inoculation with conidia using the puncture leaf test as described by Sjödin and Glimelius (1988). In all, 20 plants of each genotype were used and the experiment was repeated twice. The $B$. napus plants were inoculated on both the cotyledons and the adult leaves at plant stage BBCH 12 (Lancashire et al. 1991). The fungal isolates used were PHW 1245 and PHW 950:14 (Leroy), assigned to the race AV1-2-4-5-6-7-8 and AV1-2-3-56-9 respectively (Balesdent et al. 2005). Arabidopsis and B. napus plants were scored 10 to $21 \mathrm{dpi}$ using the scoring scale of Delwiche and Williams (1979), where $0=$ no symptoms; 1 $=$ lesion diameter 0.5 to $1.5 \mathrm{~mm} ; 3=$ dark necrotic lesions, 1.5 to $3 \mathrm{~mm} ; 5=$ lesions 3 to $5 \mathrm{~mm}$, occasional sporulation; $7=$ gray-green tissue collapse, lesions 4 to $8 \mathrm{~mm}$, sporulation; and 9 = rapid tissue collapse, accompanied of profuse sporulation in large lesions (more than $5 \mathrm{~mm}$ ). 
Chemical treatments prior inoculation.

Solutions containing $25 \mu \mathrm{M}$ ABA (Sigma Aldrich, Steinheim, Germany) or BABA at $16 \mathrm{mg} /$ liter (Sigma Aldrich) were applied to the soil in each pot to obtain an optimal distribution in the plant leaves (Jakab et al. 2001). BABA treatments of the plant material were performed 2 days preinoculation. Studies on ABA-induced resistance on Arabidopsis and B. napus were made using a 25- $\mu \mathrm{M}$ ABA (Sigma Aldrich) treatment 2 days preinoculation and $3 \mathrm{dpi}$. Controls were treated with and equal volume of water.

\section{RNA isolation.}

Leaves from inoculated plants were collected $48 \mathrm{~h}$ after inoculation. The plant material was ground in liquid nitrogen and total RNA was prepared using a Qiagen Plant minikit (Qiagen GmbH, Hilden, Germany) according to the manufacturer's instructions.

\section{Probes and hybridization.}

Total RNA $(6 \mu \mathrm{g})$ was denatured and transferred onto a Hybond- $\mathrm{N}^{+}$nylon membrane (Amersham Pharmacia Biotech, Uppsala, Sweden). The $P R-1$ and $P D F 1.2$ genes used as probes were described previously by Uknes and associates (1992) and Penninckx and associates (1996), respectively. The GSL5 (At4g03550) probe was generated from Arabidopsis genomic DNA using primers TCTTGGTCCTCCGGTTTTTCT and TCGCCTTTTGATTTCTTCCC and the VSP2 (At5g24770) probe was amplified from Arabidopsis DNA using the primers TCTCACTTTCACTTCTCTTGCTC and ATAAGCCTCTTTG CACACGGTT. The primers were designed from CDS sequences in the AGI database on domains with as low a sequence similarity to other transcripts as possible. The ABII probe was amplified using the caps markers described by Leung and associates (1997). The PCR cycle was $95^{\circ} \mathrm{C}$ for $60 \mathrm{~s} ; 35$ cycles of $95^{\circ} \mathrm{C}$ for $30 \mathrm{~s}, 55^{\circ} \mathrm{C}$ for $30 \mathrm{~s}$, and $72^{\circ} \mathrm{C}$ for $30 \mathrm{~s}$; and $72^{\circ} \mathrm{C}$ for $10 \mathrm{~min}$ for final extension. The probes were labeled and hybridized as previously described by Bohman and associates (2004). For normalization of gel loading, Elongation factor $1-\alpha(E F 1-\alpha)$ was used as hybridization control (NormanSetterblad et al. 2000). Determination of differential expression between genotypes or treatments within a comparison set was made based on a one-tailed t-test.

\section{Endogenous ABA measurement \\ of whole leaves using GC/MS.}

Arabidopsis Ler-0 plants were treated with BABA by drenching the soil 2 days preinoculation (Ton and MauchMani 2004). Plants were harvested before inoculation as well as 1,3 , and $5 \mathrm{dpi}$ and frozen in liquid nitrogen. The frozen plant material was ground in liquid nitrogen and 20 to $26 \mathrm{mg}$ was taken for analysis. Each measurement was repeated with three biological replicates on pooled material from five different plants. ABA was extracted with $80 \%$ methanol and $0.02 \%$ (wt/vol) sodium diethyldithiocarbamate as antioxidant, and $2 \mathrm{ng}$ of deuterium-labeled ABA was used as the internal standard. The extraction was done in a MixerMill for $3 \min (30 \mathrm{~Hz})$ followed by continuous shaking for $1 \mathrm{~h} \mathrm{at} 4^{\circ} \mathrm{C}$. After evaporation in a Speed Vac concentrator, the samples were dissolved in $500 \mu \mathrm{l}$ of $1 \%$ acetic acid. The $\mathrm{pH}$ was adjusted to approximately 3 and the samples were applied to a C8 (EC) column (Isolute, Mid Glamorgan, U.K.) preconditioned with $2 \mathrm{ml}$ of $100 \%$ methanol and $2 \mathrm{ml}$ of $1 \%$ acetic acid. The column was washed with $2 \mathrm{ml}$ of $1 \%$ acetic acid and the sample eluted with $2 \mathrm{ml}$ of $80 \%$ methanol in $1 \%$ acetic acid. After reduction to dryness, the sample was treated as described by Edlund and associates (1995) and analyzed in a GC-mass spectrometer (Quadrex, New Haven, CT, U.S.A.) with high resolution MS ( $\mathrm{R}=5,000, \mathrm{~m} / \mathrm{z} 190.0630$ for ABAMe-TMS and m/z 194.0877 for 2H4-ABA-Me-TMS).

\section{Measurement \\ of local endogenous ABA levels using ELISA.}

Ler-0 plants were evaluated for local ABA levels after water or BABA pretreatment. Plants were harvested before inoculation as well as 1,3 , and 5 dpi. A $1-\mathrm{cm}$ transverse strip comprising the two inoculation sites of each leaf was cut out and the material was frozen immediately in liquid nitrogen. The frozen plant material was ground in liquid nitrogen and 24.5 to $28.2 \mathrm{mg}$ was taken for analysis. Each measurement was repeated with three biological replicates on pooled material from three different plants. ABA was extracted with $80 \%$ methanol. The extraction was done in a MixerMill for $3 \mathrm{~min}$ $(30 \mathrm{~Hz})$. After evaporation in a Speed Vac concentrator, the samples were dissolved in $100 \mu \mathrm{l}$ of $80 \%$ methanol and analyzed with a Phytodetekt ABA Enzyme Immunoassay Test Kit (Agdia, Elkhart, IN, U.S.A.) in an ELISA reader (Benchmark; Bio-Rad, Hercules, CA, U.S.A.) according to the manufacturer's instructions. A generalized linear model determined a linear relationship $\left(R^{2}=0.985\right)$ between percent binding ([sample optical density at $405 \mathrm{~nm}\left(\mathrm{OD}_{405}\right)$ - nonspecific binding $\left.\mathrm{OD}_{405}\right] /\left[100 \%\right.$ binding control $\mathrm{OD}_{405}-$ nonspecific binding $\left.\left.\mathrm{OD}_{405}\right]\right) \times 100 \%$ and $\ln ([\mathrm{ABA}(\mathrm{pg})])$ in the range between 2.48 and $87.5 \%$ binding or between 0.0032 and $2 \mathrm{pg}$ of (-) ABA. All samples were found in the linear range.

\section{Staining procedures.}

Leaves from Arabidopsis and B. napus were collected 2 dpi as well as when visible symptoms had developed and stained with aniline blue as described previously by Gressel and associates (2002). The presence of callose deposition was detected with a Nikon Microphot-FXA microscope under UV light and a UV2A filter (330- to 380-nm emission). The staining was repeated twice with two independent inoculation events using five to eight biological replicates of each genotype.

\section{Callose quantification.}

TIFF pictures were taken under identical conditions, 8 to 10 aniline blue-stained leaves per genotype, and were analyzed in APS assess software (L. Lamari, University of Manitoba, Canada). Individual quantifications were based on the relative area covered by callose depositions within $0.15 \mathrm{~mm}$ of the inoculation site after background adjustments. The mean and median values for each inoculation site were used as estimators of callose deposition for each leaf sample and compared using a one-tailed $t$ test.

\section{Microarray hybridizations.}

The genetic identity of the abil-1 and abi2-1 mutants was confirmed with CAPS markers as described by Leung and associates (1997) prior to microarray comparisons. Differential gene expression in pooled ABA pretreated abil-1 and abi2-1 mutants inoculated with L. maculans was assessed 48 hpi. RNA was isolated using the RNeasy kit (Qiagen $\mathrm{GmbH}$ ). The cDNA synthesis, slide hybridization, and washings were performed as described in the protocols "RNA amplification and labeling of RNA probes" and "Microarray hybridization-RNA probes" from the Meyerowitz lab at Caltech (Pasadena, CA, U.S.A). Labeled cDNA was hybridized to CATMA 25k cDNA arrays. The experiment was done using three biological replicates and one of the replicates was dye swapped. The CATMA arrays were analyzed with GenePix 4000B (Axon Instruments, Amersham Pharmacia Biotech). 


\section{Analysis of expression data.}

Array-by-array examinations were made by the arbitrary twofold expression difference determination, after filtering and normalizations with the kth package in $\mathrm{R}$ ( $\mathrm{R}$ Foundation for Statistical Computing, Vienna, Austria) in accordance to the settings presented in the kth package tutorial. Simultaneous analysis on all three arrays was performed with a B-test within the same program package to identify significantly differentially expressed genes under the same filtering and normalization conditions. Data were uploaded in accordance to the MIAME standard to BASE for worldwide public access.

\section{Real time PCR.}

Quantitative measurements of At1g63750 (forward primer: 5'-AGCTTTGACTGAGTGAGCAAT-3', reverse primer: 5'TTCTTGATCATGTTCGCTTCAT-3'), At1g63870 (forward primer: 5'-AAGAACCTTGGAAACACAAGATTT-3', reverse primer: 5'-TGATATGCCGGACATAGCTTTA-3'), At1g63880 (forward primer: 5'-CAATGAAACTTGTGCACGTAAGA-3', reverse primer: 5'-TCGATCATTATAGCTTCATTGTCC-3'), and At1g64070 (forward primer: 5'-AGATAGCCGGCTCGAG TACC-3', reverse primer: 5'-GAACCTTCCAAATTTAGCTTC TTG-3') were done on pooled material from six individual plants $48 \mathrm{hpi}$, using four biological replicates. The PCR conditions were $2 \mathrm{~min}$ at $50^{\circ} \mathrm{C}$ and $10 \mathrm{~min}$ at $95^{\circ} \mathrm{C}$, followed by 40 cycles of $15 \mathrm{~s}$ at $95^{\circ} \mathrm{C}$ and $50 \mathrm{~s}$ at $64^{\circ} \mathrm{C}$. Genomic DNA was amplified using $3 \mu \mathrm{M}$ primers, $5 \mathrm{ng}$ of template DNA per $25 \mu \mathrm{l}$ of reaction together with $12.5 \mu \mathrm{l}$ of Power SYBR Green PCR Master mix (Applied Biosystems, Foster City, CA, U.S.A.) on a ABI 7000 thermocycler (Applied Biosystems).

\section{ACKNOWLEDGMENTS}

The authors are grateful to M. A. Torres, B. Mauch-Mani, J. Leung, P. Schulze-Lefert, and $\mathrm{H}$. Thordal-Christensen for kindly providing various Arabidopsis genotypes; S. Pedras for the gift of synthetic camalexin; and Svalöf Weibull AB for the B. napus cultivars. We also want to thank $\mathrm{R}$. Hopkins for language corrections. This research was supported by the Wallenberg Foundation, the Helge Ax:son Johnsons Foundation, the national graduate research schools in Functional Genomics and Bioinformatics (FGB), and Interactions between Micro-Organisms and Plants (IMOP) at the Swedish University of Agricultural Sciences.

\section{LITERATURE CITED}

Anderson, J. A., Badruzsaufari, E., Schenk, P. M., Manners, J. M., Desmond, O. J., Ehlert, C., Maclean, D. J., and Kazan, K. 2004. Antagonistic interaction between abscisic acid and jasmonate-ethylene signaling pathways modulates defence gene expression and disease resistance in Arabidopsis. Plant Cell 16:3460-3479.

Audenaert, K., Meye. G., and Höfte, M. 2002. Abscisic acid determines basal susceptibility of tomato to Botrytis cinerea and suppresses salicylic acid-dependent mechanisms. Plant Physiol. 128:491-501.

Balesdent, M. H., Barbetti, M. J., Li, H., Sivasithamparam, K., Gout, L., and Rouxel T. 2005. Analysis of Leptosphaeria maculans race structure in a worldwide collection of isolates. Phytopathology 95:1061-1071.

Beffa, R., Hofer, R., Thomas, M., and Meins, F. 1996. Decreased susceptibility to viral disease of $\beta$-1,3-glucanase-deficient plants generated by antisense transformation. Plant Cell 8:1001-1011.

Bohman, S., Staal, J., Thomma, B. P. H. J., Wang, M., and Dixelius, C. 2004. Characterisation of an Arabidopsis-Leptosphaeria maculans pathosystem: Resistance partially requires camalexin biosynthesis and is independent of salicylic acid, ethylene and jasmonic acid signaling. Plant J. 37:9-20.

Bright, J., Desikan, R., Hancock, J. T., Weir, I. S., and Neill, S. J. 2006 ABA-induced NO generation and stomatal closure in Arabidopsis are dependent on $\mathrm{H}_{2} \mathrm{O}_{2}$ synthesis. Plant J. 45:113-122.

Chen, C., and Howlett, B. 1996. Rapid necrosis is associated with the arrest of fungal growth in leaves of Indian mustard (Brassica juncea) inoculated with avirulent isolates of Leptosphaeria maculans. Physiol. Mol. Plant Pathol. 48:73-81.

Chini, A., Grant, J., Seki, M., Shinozaki, K., and Loake, G. 2004. Drought tolerance by enhanced expression of the $C C-N B S-L R R$ gene, $A D R 1$, requires salicylic acid, EDS1 and ABI1. Plant J. 38:810-822.

Delaney, T. P., Uknes, S., Vernooij, B., Friedrich, L., Weymann, K., Negretto, D., Gaffney, T., Gut-Rella, M., Kessmann, H., Ward, E., and Ryals, J. 1994. A central role of salicylic acid in plant disease resistance. Science 266:1247-1250.

Delwiche, P. A., and Williams, P. H. 1979. Screening for resistance to blackleg of crucifers in the seedling stage. Cruciferae Newsl. 4:24.

Desikan, R., Griffiths, R., Hancock, J., and Neill, S. 2002. A new role for an old enzyme: Nitrate reductase mediated nitric oxide generation is required for abscisic acid-induced stomatal closure in Arabidopsis thaliana. Proc. Natl. Acad. Sci. U.S.A. 99:16314-16318.

Donofrio, N. M., and Delaney, T. P. 2001. Abnormal callose response phenotype and hypersusceptibility to Peronospora parasitica in defensecompromised Arabidopsis nim1-1 and salicylate hydroxylase-expressing plants. Mol. Plant-Microbe Interact. 14:439-50.

Edlund, A., Eklöf, S., Sundberg, B., Moritz, T., and Sandberg, G. 1995. A microscale technique for gas chromatography-mass spectrometry of picogram amounts of indole-3-acetic acid in plant tissues. Plant Physiol. 108:1043-1047.

Fedoroff, N. 2002. Cross-talk in abscisic acid signaling. Science's STKE 140:RE10 1-12.

Finkelstein, R. R. 1994. Mutations at two new Arabidopsis ABA response loci are similar to the abi3 mutations. Plant J. 5:765-771.

Flors, V., Ton, J., Jakab, G., and Mauch-Mani, B. 2005. Abscisic acid and callose: Team players in defence against pathogens? J. Phytopathol. 153:377-383

Glazebrook, J. 2005. Contrasting mechanisms of defense against biotrophic and necrotrophic pathogens. Annu. Rev. Phytopathol. 43:205-227.

Glazebrook, J., and Ausubel, F. M. 1994. Isolation of phytoalexin-deficient mutants of Arabidopsis thaliana and characterization of their interactions with bacterial pathogens. Proc. Natl. Acad. Sci. U.S.A. 9:89558959

Gosti, F., Beaudoin, N., Serizet, C., Webb, A., Vartanian, N., and Giraudat, J. 1999. ABI1 protein phosphatase $2 \mathrm{C}$ is a negative regulator of abscisic acid signaling. Plant Cell 11:1897-1909.

Gressel, J., Michaeli, D., Kampel, V., Amsellem, Z., and Warshawsky, A. 2002. Ultra low calcium requirement of fungi facilitate use of calcium regulating agents to suppress host calcium-dependent defenses, synergizing infection by a mycoherbicide. J. Agric. Food. Chem. 50:63536360 .

Guimaraes, R. L., and Stotz, H. U. 2004. Oxalate production by Sclerotinia sclerotiorum deregulates guard cells during infection. Plant Physiol. 136:3703-3711.

Guo, F., Okamoto, M., and Crawford, N. 2003. Identification of a plant nitric oxide synthase gene involved in hormonal signaling. Science 302:100-103

Hammond-Kosack, K. E., and Parker, J. E. 2003. Deciphering plant-pathogen communication: Fresh perspectives for molecular resistance breeding. Curr. Opin. Biotechnol. 14:177-193.

Hoth, S., Morgante, M., Sanchez, J., Hanafey, M., Tingey, S., and Chua, N. 2002. Genome-wide expression profiling in Arabidopsis thaliana reveals new targets of abscisic acid and largely impaired gene regulation in the abil-1-1 mutant. J. Cell Sci. 115:4891-4900.

Howlett, B., Idnurm., A., and Pedras, M. S. C. 2001. Leptosphaeria maculans, the causal agent of blackleg disease of Brassicas. Fungal Genet. Biol. 33:1-14.

Jakab, G., Cottier, V., Toquin, V., Rigoli, G., Zimmerli, L., Métraux, J., and Mauch-Mani, B. 2001. $\beta$-Aminobutyric acid-induced resistance in plants. Eur. J. Plant Pathol. 107:29-37.

Jakab, G., Ton, J., Flors, V., Zimmerli, L., Metraux, J., and Mauch-Mani, B. 2005. Enhancing Arabidopsis salt and drought stress tolerance by chemical priming for its abscisic acid responses. Plant Physiol. 139:267-274.

Klessig, D., Durner, J., Noad, R., Navarre, R., Wendehenne, D., Kumar, D., Zhou, J., Shah, J., Zhang, S., Kachroo, P., Trifa, Y., Pontier, D. Lam, E., and Silva, H. 2000. Nitric oxide and salicylic acid signaling in plant defense. Proc. Natl. Acad. Sci. U.S.A. 97:8849-8855.

Klüsener, B., Young, J., Murata, Y., Allen, G., Mori, I., Hugouvieux, V., and Schroeder, J. 2002. Convergence of calcium signaling pathways of pathogenic elicitors ant abscisic acid in Arabidopsis guard cells. Plant Physiol. 130:2152-2163.

Koornneef, M., Jorna, M. L., Brinkhorst-van der Swan, D. L. C., and Karssen, C. M. 1982. The isolation of abscisic acid (ABA) deficient mutants by selection of induced revertants in non-germinating gibberellin sensitive lines of Arabidopsis thaliana (L.) Heynh. Theor. Appl. Genet. 61:385-393

Koornneef, M., Reuling, G., and Karssen, C. M. 1984. The isolation and characterization of abscisic acid-insensitive mutants of Arabidopsis thaliana. Physiol. Plant. 61:377-383.

Kwak, J., Mori, I., Pei, Z., Leonhardt, N., Torres, M., Dangl, J., Bloom, R., 
Bodde, S., Jones, J., and Schroeder, J. 2003. NADPH oxidase AtrbohD and AtrbohF genes function in ROS-dependent ABA signaling in Arabidopsis. EMBO (Eur. Mol. Biol. Organ.) J. 22:2623-2633.

Lancashire, P. D., Bleiholder, H., Van den Boom, T., Langelüddecke, P., Stauss, R., Weber, E., and Witzenberger, A. 1991. A uniform decimal code for growth stages of crops and weeds. Ann. Appl. Biol. 119:561-601.

Léon-Kloosterziel, K. M., Gil, M. A., Ruijs, G. J., Jacobsen, S. E., Olszewski, N. E., Schwartz, S. H., Zeevaart, J. A. D., and Koornneef, M. 1996. Isolation and characterization of abscisic acid-deficient Arabidopsis mutants at two new loci. Plant J. 10:655-661.

Leung, J., Merlot, S., and Giraudat, J. 1997. The Arabidopsis ABSISCIC $A C I D$-INSENSITIVE2 (ABI2) and ABI1 genes encode homologous protein phosphatase $2 \mathrm{C}$ involved in abscisic acid signal transduction. Plant Cell 9:759-771.

Li, C., and Cowling, W. 2003. Identification of a single dominant allele for resistance to blackleg in Brassica napus 'Surpass 400'. Plant Breed. 122:485-488

Mateo, A., Mühlenbock, P., Rustérucci, C., Chi-Chen Chang, C., Miszalski, Z., Karpinska, B., Parker, J., Mullineaux, P., and Karpinski, S. 2004. LESION SIMULATING DISEASE 1 is required for acclimation to conditions that promote excess excitation energy. Plant Physiol. 136:2818-2830.

Mauch-Mani, B., and Mauch, F. 2005. The role of abscisic acid in plantpathogen interactions. Curr. Opin. Plant Biol. 8:409-414.

McDonald, K., and Cahill, D. 1999. Influence of abscisic acid and the abscisic acid biosynthesis inhibitor, norflurazon, on interactions between Phytophthora sojae and soybean (Glycine max). Eur. J. Plant Pathol. 105:651-658.

Merlot, S., Gosti, F., Guerrier, D., Vavasserur, A., and Giraudat, J. 2001. The $\mathrm{ABI}$ and $\mathrm{ABI} 2$ protein phosphatases $2 \mathrm{C}$ act in a feedback regulatory loop of the abscisic acid signaling pathway. Plant J. 25:259-303.

Mohr, P., and Cahill, D. 2003. Abscisic acid influences the susceptibility of Arabidopsis thaliana to Pseudomonas syringae pv. tomato and Peronospora parasitica. Funct. Plant Biol. 30:461-469.

Norman-Setterblad, C., Vidal, S., and Palva, E. T. 2000. Interacting signal pathways control defense gene expression in Arabidopsis in response to cell wall-degrading enzymes from Erwinia carotovora. Mol. PlantMicrobe Interact. 13:430-438.

Noutoshi, Y., Ito, T., Seki, M., Nakashita, H., Yoshida, S., Marco, Y., Shirasu, K., and Shinozaki, K. 2005. A single amino acid insertion in the WRKY domain of the Arabidopsis TIR-NBS-LRR-WRKY-type disease resistance protein SLH1 (sensitive to low humidity 1) causes activation of defense responses and hypersensitive cell death. Plant J. 43:873-888

Penninckx, I. A., Eggermont, K., Terras, F. R., Thomma, B. P., De Samblanx, G. W., Buchala, A., Metraux, J. P., Manners, J. M., and Broekaert, W. F. 1996. Pathogen induced systemic activation of a plant defensin gene in Arabidopsis follows a salicylic acid-independent pathway. Plant Cell 8:2309-2323.

Rezzonico, E., Flury, N., Meinz, F., and Beffa, R. 1998. Transcriptional down-regulation by abscisic acid of pathogenesis-related $\beta$-1,3-glucanase genes in tobacco cell cultures. Plant Physiol. 117:585-592.

Saez, A., Aposolova, N., Gonzalez-Guzman, M., Gonzalez-Garcia, M., Nicolas, C., Lorenzo, O., and Rodriguez, P. 2004. Gain-of-function and loss-of-function phenotypes of the protein phosphatase 2C HAB1 reveal its role as a negative regulator of abscisic acid signaling. Plant J. 37:354-369.

Salisbury, P. A., Ballinger, D. J., Wratten, N., Plummer, K., and Howlett, B. J. 1995. Blackleg disease on oilseed Brassica in Australia: A review. Aust. J. Exp. Agric. 35:665-672.

Sánchez, J.-P., Duque, P., and Chua, N.-H. 2004. ABA activates ADPR cyclase and cADPR induces a subset of ABA-responsive genes in Arabidopsis. Plant J. 38:381-395.

Sanderfoot, A. A., Assaad, F. F., and Raikhel, N. V. 2000. The Arabidopsis genome: An abundance of soluble $N$-ethylmaleimide-sensitive factor adaptor protein receptors. Plant Physiol. 124:1558-1569.

Schmid, M., Davison, T., Henz, S., Pape, U., Demar, M., Vingron, M, Scholkopf, B., Weigel, D., and Lohmann, J. 2005. A gene expression map of Arabidopsis thaliana development. Nat. Genet. 37:501-506.

Schröder, M., Dixelius, C., Råhlén, L., and Glimelus, K. 1994. Transformation of B. napus by using the aadA gene as the selectable marker and inheritance studies of the marker genes. Physiol. Plant. 92:37-44.

Seki, M., Ishida, J., Narusaka, M., Fujita, M., Nanjo, T., Umezawa, T., Kamiya, A., Nakajima, M., Enju, A., Sakurai, T., Satou, M., Akiyama, K., Yamaguchi-Shinozaki, K., Carninci, P., Kawai, J., Hayashizaki, Y., and Shinozaki, K. 2002. Monitoring the expression patterns of around 7,000 Arabidopsis genes under ABA treatments using a full-length cDNA microarray. Funct. Integr. Genomics 2:282-291.
Sjödin, C., and Glimelius, K. 1988. Screening for resistance to blackleg Phoma lingam (Tode ex Fr.) Desm. within Brassicaceae. J. Phytopathol. 123:322-332.

Söderman, E., Brocard, I., Lynch, T., and Finkelstein, R. 2000. Regulation and function of the Arabidopsis ABA-insensitive4 gene in seed and abscisic acid response signaling networks. Plant Physiol. 124:1752-1765.

Staal, J., Kaliff, M. Bohman, S., and Dixelius, C. 2006. Transgressive segregation reveals two Arabidopsis TIR-NB-LRR resistance genes effective against Leptosphaeria maculans, causal agent of blackleg disease. Plant J. 46:218-230.

Thaler, J. S., and Bostock, R. M. 2004. Interactions between abscisic-acidmediated responses and plant resistance to pathogens and insects. Ecology 85:48-58.

Tierens, K. F. M.-J., Thomma, B. P. H. J., Bari, R. P., Garmier, M., Eggermont, K., Brouwer, M., Penninckx, I. A. M. A., Broekaert, W. F., and Cammue, B. P. A. 2002. Esal, an Arabidopsis mutant with enhanced susceptibility to a range of necrotrophic fungal pathogens, shows a distorted induction of defense responses by reactive oxygen generating compounds. Plant J. 29:131-140.

Ton, J., and Mauch-Mani, B. 2004. $\beta$-Aminobutyric acid resistance against two necrotrophic pathogens is based on ABA-dependent priming for callose. Plant J. 38:119-130.

Ton, J., Jakab, G., Toquin, V., Iavicoli, A., Maeder, M., Metraux, J., and Mauch-Mani, B. 2005. Dissecting the beta-aminobutyric acid-induced priming phenomenon in Arabidopsis. Plant Cell 17:987-999.

Torres, M., and Dangl, J. 2005. Functions of the respiratory burst oxidase in biotic interactions, abiotic stress and development. Curr. Opin. Plant Biol. 8:397-403.

Torres, M., Dangl, J. and Jones, J. 2002. Arabidopsis gp $91^{\text {phox }}$ homologues AtrbohD and AtrbohF are required for accumulation of reactive oxygen species in the plant defense response. Proc. Natl. Acad. Sci. U.S.A. 99:517-522.

Torres, M., Jones, J., and Dangl, J. 2005. Pathogen induced, NADPH oxidase-derived reactive oxygen intermediates suppress spread of cell death in Arabidopsis thaliana. Nat. Genet. 37:1130-1134.

Uknes, S., Mauch-Mani, B., Moyer, M., Potter, S., Williams, S., Dincher, S., Chandler, D., Slusarenko, A., Ward, E., and Ryals, J. 1992. Acquired resistance in Arabidopsis. Plant Cell 4:645-656.

van Wees. S. C., and Glazebrook, J. 2003. Loss of non-host resistance of Arabidopsis NahG to Pseudomonas syringae pv. phaseolicola is due to degradation products of salicylic acid. Plant J. 33:733-742.

Vogel, J., and Somerville, S.C. 2000. Isolation and characterization of powdery mildew-resistant Arabidopsis mutants. Proc. Natl. Acad. Sci. U.S.A. 97:1897-1902.

Whenham, R. J., Fraser, R. S. S., Brown, L. P., and Payne, J. A. 1986. Tobacco mosaic virus-induced increase in abscisic acid concentration in tobacco leaves: Intracellular location in light and dark green areas, and relationship to symptom development. Planta 168:592-598.

Xiong, L., Lee, H., Ishitani, M., and Zhu, J. 2002. Regulation of osmotic stress-responsive gene expression by the LOS6/ABA1-3 locus in Arabidopsis. J. Biol. Chem. 277:8588-8596.

Yang, Y., Sulpice, R., Himmelbach, A., Meinhard, M., Christmann, A., and Grill, E. 2006. Fibrillin expression is regulated by abscisic acid response regulators and is involved in abscisic acid-mediated photoprotection. Proc. Natl. Acad. Sci. U.S.A. 103:6061-6066.

Zeevaart, J. A. D., and Creelman, R. A. 1988. Metabolism and physiology of abscisic acid. Annu. Rev. Plant Physiol. Plant Mol. Biol 39:439-473.

Zimmerli, L., Jakab, G., Métraux, J., and Mauch-Mani, B. 2000. Potentiation of pathogen-specific defence mechanisms in Arabidopsis by $\beta$-aminobutyric acid. Proc. Natl. Acad. Sci. U.S.A. 97:12920-12925.

Zimmerli, L., Métraux, J., and Mauch-Mani, B. 2001. $\beta$-Aminubutyric acid induced protection of Arabidopsis against the necrotrophic fungus Botrytis cinerea. Plant Physiol. 126:517-523.

Zimmermann, P., Hirsch-Hoffmann, M., Hennig, L., and Gruissem, W. 2004. GENEVESTIGATOR. Arabidopsis microarray database and analysis toolbox. Plant Physiol. 136:2621-2632.

\section{AUTHOR-RECOMMENDED INTERNET RESOURCES}

The Arabidopsis Information Resource AGI database: www.arabidopsis.org

Caltech protocols: www.its.caltech.edu/ plantlab/html/protocols.html www.catma.org

KTH (Royal Institute of Technology, Stockholm) microarray resource center website: www.biotech.kth.se/molbio/microarray

The Linnaeus Centre for Bioinformatics (BASE) database: base.lcb.uu.se/

Additional keywords not included in the print version were added to the online version on October 29, 2007. 